\title{
The Use of Japanese Personal Pronoun based on Gender in "Narcissu" by Tomo Kataoka
}

\author{
Hadiid Hideo Nusantara \\ Universitas Padjadjaran, Bandung, Indonesia \\ hadiidhideo8@gmail.com
}

\begin{abstract}
A B S T R A C T
This article discussed the difference of Japanese pronouns based on gender from literature point of view. The database of this study was a novel entitled "Narcissu" by Japanese author Tomo Kataoka. The research method used in this research was descriptive method. In analysing the novel, author used the morphology theories by Harumi Tanaka (1982). The findings of this study showed that the use of personal pronoun including first-person pronouns, second-person pronouns, and thirdperson pronouns in the novel were influenced greatly by gender. The difference in using these personal pronouns were caused by the difference in man and woman's perception. Based on the data, there were tendency that the speakers choose the best word to utter to their interlocutor based on their own perspective, influenced by the situation and the context. The findings of this study was expected to help foreign language learners to understand better about the use of Japanese personal pronoun based on gender, mainly in conversation.
\end{abstract}

Gender; Language variety; Morphology; Personal Pronoun

\section{K E Y W O R D S}

$\begin{array}{lrr} & \text { A R T I C L E I N F O } & \text { First received: } 18 \text { December } 2019 \\ \text { Final proof accepted: } 15 \text { May } 2020\end{array}$

Available online: 20 June 2020

\section{PENDAHULUAN}

Bahasa Jepang sangat dipengaruhi oleh faktorfaktor luar bahasa, seperti faktor situasional, sosial, stratifikasi, ekonomi, umur, dan gender. Faktor gender yang mengakibatkan terjadinya perbedaan variasi bahasa yang terlihat di dalam penutur pria dan penutur wanita. Gender pada penelitian ini merujuk kepada bahasa yang khusus digunakan oleh pria yang disebut "danseigo" (男性語) dan bahasa yang khusus digunakan oleh wanita yang disebut "joseigo" (女性語). Hal ini disebabkan karena pada kenyataannya, bahasa Jepang tidaklah memiliki sistem gender dalam kategori gramatikal seperti halnya bahasa Perancis maupun bahasa sejenis lainnya.

Nomina, atau dalam bahasa Jepang disebut meishi (名詞), adalah kategori yang secara sintaktis tidak dapat bergabung dengan morfem "tidak", tetapi dapat didahului oleh "dari", dan dari segi semantis, nomina adalah kata yang merujuk pada nama seseorang, tempat, atau semua benda dan segala yang dibendakan (Kridalaksana, 1992). 
Menurut Sudjianto dan Dahidi (2012), nomina terbagi atas lima kelompok, yaitu:

1. Nomina umum (Futsuumeishi) merupakan nomina yang menyatakan nama-nama benda, barang, peristiwa, dan sebagainya yang bersifat umum. Misalnya 山 (yama) 'gunung', 本 (hon) 'buku', 学校 (gakkou) 'sekolah', 世界 (sekai) 'dunia', dan 星 (hoshi) 'bintang'.

2. Nomina diri (Koyuumeishi) merupakan nomina yang menyatakan nama-nama yang menunjukkan benda secara khusus seperti nama-nama daerah, nama-nama negara, nama orang, nama buku, dan sebagainya. Misalnya 太平洋 (Taiheiyou) 'Samudera Pasifik', インド ネシア (Indonesia), 日本 (Nihon) 'Jepang', 富 士山 (Fujisan) 'Gunung Fuji', 韓国 (Kankoku) 'Korea'.

3. Nomina formal (Keishikimeishi) merupakan nomina yang menerangkan fungsinya secara formalitas tanpa memiliki hakekat atau arti yang sebenarnya sebagai sebuah nomina. Menurut Murata (dalam Rini, 2018), keishiki meishi adalah nomina yang digunakan untuk memodifikasi kata yang lain dan nomina yang hampir tidak digunakan secara tunggal yang memiliki arti substansial, misalnya: こと (koto), ため (tame), わけ (wake), はず (hazu), まま (mama), とおり (toori), 場合 (baai), dan sebagainya.

4. Nomina numeral (Suushi) merupakan nomina yang menyatakan bilangan, jumlah, kuantitas, urutan dan sebagainya. Misalnya 三つ (mitsu) 'tiga', 七人 (shichi nin) 'tujuh orang', 第一 (daiichi) 'pertama', 五本 (gohon) 'lima batang'.

5. Pronomina (Daimeishi) merupakan nomina yang menunjukkan sesuatu tanpa menyebutkan nama orang, benda, barang, perkara, arah, tempat, dan sebagainya. Katakata yang dipakai untuk menunjukkan orang disebut dengan ninshou daimeishi (pronomina persona), sedangkan kata-kata yang dipakai untuk menunjukkan benda, barang, perkara, arah, dan tempat disebut dengan shiji daimeishi (pronomina penunjuk). Misalnya この (kono) 'ini', その (sono) 'itu', あの (ano) 'itu', これ (kore) 'ini', それ (sore) 'itu', あれ (are) 'itu', ここ (koko) 'di sini'，そこ (soko) 'di situ'，あそこ (asoko) 'di sana', あなた (anata) 'kamu', わたし (watashi) 'saya', かのじょ (kanojo) 'dia', dan sebagainya.
Akan tetapi, ada sedikit tambahan jenis kata nomina yang ada pada bahasa Jepang, yaitu:

1. Nomina Abstrak (Chuushoumeishi) di mana nomina bersifat abstrak seperti 命 (inochi) 'jiwa', 平和 (heiwa) 'kedamaian', dan sebagainya.

2. Nomina keterangan (Tenseimeishi) di mana kelas kata lain selain nomina diproses menjadi nomina (nominalisasi), contohnya adalah 滅び (horobi) 'kehancuran', 嬉 しさ (ureshisa) 'kesenangan', dan sebagainya.

Alwi, Soenjono, Lapoliwa, dan Moeliono (2003) menyebutkan bahwa sebagian besar pronomina persona bahasa Indonesia memiliki lebih dari dua wujud. Hal ini disebabkan oleh adanya budaya bangsa kita yang sangat memperhatikan hubungan sosial antar manusia. Tata krama dalam kehidupan bermasyarakat kita menuntut adanya aturan yang serasi dan sesuai dengan martabat masing-masing. Berbagai jenis Pronomina Persona adalah sebagai berikut.

1. Persona Pertama

Pronomina persona pertama adalah pronomina yang mengacu pada diri sendiri. $\mathrm{Di}$ samping pronomina persona pertama tunggal juga ada pronomina persona pertama jamak.

2. Persona Kedua

Pronomina persona kedua adalah pronomina yang mengacu pada orang yang diajak bicara. Pronomina persona kedua ini ada yang mengacu pada banyak orang dan ada yang mengacu pada hanya satu orang. Pronomina persona yang mengacu pada satu orang disebut dengan pronominal persona kedua tunggal, dan pronomina persona kedua yang mengacu pada banyak orang disebut dengan pronomina persona kedua jamak.

3. Persona Ketiga

Pronomina persona ketiga adalah pronomina yang mengacu pada orang yang dibicarakan. Pronomina persona ketiga ini juga ada yang mengacu pada banyak orang dan ada yang mengacu pada hanya satu orang. Pronomina persona yang mengacu pada satu orang disebut dengan pronomina persona ketiga tunggal. Pronomina persona ketiga yang mengacu pada banyak orang disebut dengan pronomina persona ketiga jamak.

Sama seperti bahasa Indonesia, pronomina persona dalam bahasa Jepang juga terbagi ke dalam tiga jenis, yaitu kata ganti orang pertama 
yang disebut ichininshou daimeishi, kedua yang disebut nininshou daimeishi dan ketiga yang disebut sanninshou daimeishi. kata ganti orang pertama yaitu, saya (watashi/ washi/ware), aku (ore/boku) (singularis), kami (watashitachi/bokura/wareware) (pluralis), dan kita (pluralis: orang kedua ikut serta) (bahasa Jepang tidak membedakan antara "kami" dan "kita"); kata ganti orang kedua, yaitu "anda" (anata/nanji), "kamu" (omae), "engkau" (kimi) (singularis), dan "kalian" (anatatachi/omaera) (pluralis); serta kata ganti orang ketiga, yaitu "orang itu" (ano hito), "dia (laki-laki/perempuan)" (kare/kanojo) (singularis), dan "mereka" (anohitotachi/karera) (pluralis).

Tanaka (1982) membagi kosa kata yang digunakan berdasarkan gender ke dalam 4 bagian, yaitu joseigo (Bahasa Perempuan), danseigo (Bahasa Laki-laki), tsuuseigo (Bahasa Umum), dan chuuseigo (Bahasa Netral). Namun dalam bahasa Jepang tidak ada bahasa netral. Pembentukkan kata gender pun pada umumnya bukan karena adanya makna leksikal melainkan karena adanya makna gramatikal.

Jorden (dalam Sudjianto \& Dahidi, 2004) menyatakan bahwa bahasa Jepang memiliki karakteristik berupa adanya gaya bahasa yang secara tegas membedakan jenis kelamin. Danseigo merupakan ragam bahasa yang secara khusus digunakan oleh laki-laki. Misalnya ore (aku) dan omae (kamu). Sedangkan joseigo adalah ragam bahasa yang secara khusus digunakan oleh kaum wanita. Akan tetapi menurut Takamizawa (dalam Sudjianto \& Dahidi, 2004), pada situasi formal hampir tidak ada perbedaan antara laki-laki dan wanita.

Penelitian yang dilakukan oleh Yuana (2018) mengenai perbedaan pronomina persona pertama berdasarkan gender memberikan banyak contoh penggunaan pronomina yang ada pada bahasa Jepang. Salah satunya seperti contoh berikut.

\section{私は自動車に泥水をかけられた。}

Watashi wa jidousha ni doromizu o kakerareta.

'Saya tersiram genangan air kotor oleh mobil lewat.

(Yukiko, 1989, hal.21 dalam Yuana, 2018)

Pada contoh kalimat di atas, watashi digunakan untuk menunjuk dirinya sendiri tanpa bermaksud untuk merendahkan diri atau meninggikan orang lain, karena kata watashi bersifat umum dan lazim digunakan dalam semua situasi, baik situasi formal maupun informal, dan bisa digunakan pada semua kalimat baik kalimat tanya, kalimat berita dan sebagainya.

Penelitian di atas sangat membantu dalam mempelajari penggunaan kalimat bahasa Jepang bagi penutur asing. Tetapi, penelitian tersebut hanya memberikan penjelasan terhadap pronominal persona pertama saja, sedangkan dalam bahasa Jepang pronomina persona terbagi atas tiga sudut pandang. Maka dari itu, penelitian ini diharapkan dapat mengisi kekosongan yang ada di penelitian terdahulu, agar dapat meningkatkan penelitian dalam bidang kebahasaan ke jenjang yang lebih tinggi.

Penelitian ini menggunakan novel sebagai data primer. Penggunaan novel sebagai data disebabkan oleh kerelevansian yang tercerminkan oleh novel, sangat berkaitan dengan dunia nyata. Menurut Luxemburg (1989) dalam Artika (2015) karya sastra bisa mencerminkan kenyataan, sastra sering juga dituntut agar mencerminkan atau merepresentasikan kenyataan. Paparan tersebut menunjukkan bahwa karya sastra merupakan cerminan fenomena sosial yang terjadi karena proses pembuatannya tidak terlepas dari referensireferensi sosial yang ditemui pengarangnya di dunia nyata dan dituangkannya dalam karya tersebut.

Light novel karya Tomo Kataoka yang berjudul "Narcissu" adalah sebuah novel ringan yang menceritakan dua orang pasien rumah sakit yaitu Yuu Atou dan Setsumi Sakura yang telah masuk ke L7 (lantai 7) sebuah rumah sakit, dan diketahui bahwa hidup mereka tidak akan lama lagi. Setsumi tidak ingin mengakhiri hidupnya di rumah sakit maupun di rumahnya sendiri. Salah satu contoh yang menarik perhatian peneliti terhadap novel ini adalah banyaknya penggunaan pronomina persona yang tercermin di dalam teks novel tersebut. Salah satunya pada contoh berikut.

\footnotetext{
俺の名前や血液型が記載された、そのいろが青か ら白へと変わった。

Ore no namae ya ketsueki ga kisai sareta, sono iro ga ao kara shiro e to kawatta.
}

(Kataoka, 2008, hal. 28)

俺/の/名前/や/血液型/が/記載された、/その いろ/が/青/から/白/へと/変わった。

Saya/ par/ nama/ dan/ gol.darah/ par/ dicatat/ warna itu/ Par/ biru/ par (dari)/ putih/ par (ke)/ berubah

'Nama dan gol. Darah saya dicatat, warna (gelangnya) berubah dari biru ke putih.'

(Kataoka, 2015, hal. 23) 
Kalimat ini merupakan monolog Yuu pada pembukaan cerita (prolog) yang menceritakan bahwa setelah kepindahannya ke Rumah Sakit, banyak hal yang mulai berubah pada dirinya. Akhirnya setelah didiagnosis bahwa dia harus pindah ke RS yang lebih modern agar kasusnya dapat ditangani dengan lebih baik. Gelang identitas yang ia gunakan pun berbeda dengan yang biasa ia gunakan sebelumnya.

Pada kalimat ini, Yuu menggunakan ore. Kata ganti orang pertama ini terkesan kasar dan menampilkan keakraban yang umumnya digunakan oleh pria usia remaja hingga orang tua terhadap teman atau terhadap orang yang statusnya lebih rendah.

Dari contoh kalimat di atas, kita dapat melihat bahwa gender merupakan salah satu faktor dominan dalam pemilihan kata pronomina persona. Dengan adanya penelitian terdahulu oleh Yuana (2018) mengenai perbedaan pronomina persona pertama berdasarkan gender dan penelitian Hermawan dan Rosliana (2013) mengenai penggunaan pronomina persona dalam bahasa Jepang, peneliti ingin memberikan khasanah yang lebih mendalam dalam penelitian linguistik morfologi yang fokus kepada cerminan percakapan sehari-hari masyarakat Jepang dalam sebuah karya sastra. Ini yang menjadi daya tarik bagi peneliti untuk melihat bagaimana fenomena variasi pronomina persona ini digambarkan dalam novel.

\section{METODE PENELITIAN}

Penelitian ini merupakan penelitian pustaka. Data yang digunakan berupa data primer dari novel "Narcissu" karya Tomo Kataoka berupa penggalan kalimat yang menggunakan kelas kata pronomina persona pada setiap percakapan maupun monolog pada novel. Novel tersebut dianalisis menggunakan metode deskriptif kualitatif dengan pendekatan morfologi, di mana tiap-tiap kata dipusatkan dan diperhatikan pada prinsip-prinsip umum yang mendasari perwujudan satuan-satuan gejala yang ada. Teknik yang digunakan dalam proses analisis adalah mencatat keterangan-keterangan melalui hasil pembacaan novel yang menunjukkan fenomena penghilangan pronomina agar munculnya percakapan yang implisit. Teori yang digunakan sebagai landasan dalam menganalisis adalah teori morfologi sebagai jembatan dalam pengkategorian kata dalam struktur kalimat, agar dapat mengkaji lebih lanjut mengenai terjadinya penghilangan atau pergeseran yang terjadi pada bahasa Jepang dengan hasil dari terjemahan bahasa Indonesia.

\section{HASIL DAN PEMBAHASAN}

\section{Kata Ganti Orang Pertama (Ichininshou Daimeishi)}

Penggunaan kata ganti orang pertama biasa digunakan untuk menunjuk pembicara yang menuturkan kalimat mereka. Penggunaan kata ganti ini merujuk kepada kata "aku", "saya" dan lainnya untuk menunjukkan identitas subjek dari kalimat yang dituturkan. Sebagai contohnya:

Data 1:

こんな時こそ、わたしも笑顔を向け、明るく振る 舞うべきかも知れないけど.......本当はあまり好き じゃなかったポテトを黙って食べるぐらいしかで きなかった。

Konna toki koso, watashi mau egao wo muke, akaruku maubeki kamo shirenai kedo... hontou wa amari suki janakatta poteto wo damatte taberu gurai shika dekinakatta.

(Kataoka, 2008:16)

こんな/時/こそ、/わたし/も/笑顔/を/向け、/ 明るく/振る舞う/べき/かも知れない/けじ....../ 本当/は/あまり/好き/じやな/かった/ポテト/を /黙って/食べる/ぐらい/しか/できな/かった。

Seperti ini/ waktu/ pastinya/ aku/ par/ senyum/ par/ menunjuk/ ceria/ bersikap/ harus/ mungkin/ tetapi/ benar/ par/ terlalu/ suka/ tidak/ telah/ kentang/ par/ diam/ makan/ hanya/ selain/ tidak bisa/ telah

'Pada saat makan malam yang seperti itu pun, diriku tetap saja berusaha untuk tertawa dan bersikap ceria... Namun, sebenarnya aku hanya bisa diam dan memakan kentang yang tidak begitu kusukai.'

(Kataoka, 2015, hal. 11)

Data 1 di atas merupakan monolog Setsumi saat sedang makan malam bersama kedua orangtuanya di rumah baru. Setsumi yang baru saja didiagnosa bahwa dia memiliki penyakit yang tidak dapat disembuhkan merasa hanya menjadi beban hidup bagi keluarganya. Dia yang ingin dimarahi atas ketidakmampuannya merasa depresi karena tidak dapat melakukan apa-apa. Pada akhirnya dia menyerah dan hanya dapat tersenyum untuk orang tuanya.

Kalimat data ini memiliki kesan feminim dengan penggunaan kata “わたし (watashi)” yang 
memiliki arti 'saya', dan terkesan lebih mendekati joseigo. Penggunaan kata ini memang dapat digunakan oleh kaum pria, tetapi penggunaan kata ini lebih digunakan oleh kaum wanita untuk menunjukkan keformalitasan. Sedangkan kata ganti yang sering digunakan oleh pria untuk menunjukkan keformalitasan adalah “ぼく (boku)". Penggunaan kata feminim lainnya untuk menggantikan orang pertama adalah “わたくし (watakushi)" di mana penggunaan kanjinya sama dengan kata “わたし (watashi)”, yaitu “私”、dan juga kata “あたし (atashi)” sebagai joseigo yang sering digunakan dalam bahasa nonformal. Dengan melihat pronomina persona yang digambarkan, maka kita dapat mengkonfirmasikan bahwa penutur dialog tersebut merupakan orang dengan gender wanita, yaitu Setsumi. Hal ini sesuai dengan situasi yang digambarkan bahwa kalimat ini memang merupakan bagian dari monolog Setsumi.

Pada penelitian Yuana (2018), terdapat penjelasan yang membenarkan hal di atas, bahwa watashi digunakan untuk menunjuk dirinya sendiri tanpa bermaksud untuk merendahkan diri atau meninggikan orang lain, karena kata watashi bersifat umum dan lazim digunakan dalam semua situasi, baik situasi formal maupun informal. Terkait dengan penjelasan tersebut, Yuana (2018) menggunakan contoh sebagai berikut.

Data 2.

私は自動車に泥水をかけられた。

Watashi wa jidousha ni doromizu o kakerareta.

'Saya tersiram genangan air kotor oleh mobil lewat.'

(Yukiko, 1989, hal. 21 dalam Yuana, 2018)

Data 3 di atas menunjuk kepada pemeran wanita yang memanggil dirinya dengan sebutan "watashi" dengan konteks formalitas terhadap lawan bicara yang lebih tinggi kedudukannya. pada contoh tersebut, Yuana (2018) mengungkapkan bahwa watashi biasanya digunakan oleh pria maupun wanita dengan maksud sedikit lebih akrab atau sedikit informal, dan merupakan kata ganti orang pertama tunggal untuk menunjukkan diri sendiri. Tetapi peneliti menganggap bahwa pernyataan tersebut kurang tepat, karena data yang digunakan berkontradiksi dengan pernyataan bahwa kata ini memiliki maksud sedikit lebih akrab. Jika dilihat pada data yang telah diteliti, terlihat bahwa penyebutan watashi di sini memiliki jarak antara penutur dan lawan bicara, sehingga terjadi keformalan di dalam kalimatnya.
Pada contoh selanjutnya kita juga akan melihat bagaimana penggunaan pronomina persona pertama digunakan oleh pria.

Data 3.

俺も他のみんなと同じように、自分のナンバーを 目で追う。

Ore mo hoka no minna to onaji youni, jibun no nambaa wo me de ou.

(Kataoka, 2008, hal. 18)

俺/も/他/の/みんな/と/同じ/ように/自分/の/ ナンバー/を/目/で/追う。

Aku/ par/ lain/ par/ semua/ par/ sama/ seperti/ diri sendiri/ par/ angka/ par/ mata/ par/ mengejar 'Sama seperti orang-orang lainnya, aku pun mulai mencari-cari nomor ujianku.'

(Kataoka, 2015, hal. 13)

Data 3 di atas merupakan monolog Yuu pada saat dia bersama temannya hendak melihat papan buletin ujian mengemudi. Selain Yuu dan temannya, banyak peserta lain yang ikut untuk mencari nomor peserta ujian mereka di papan elektronik yang terpampang. Yuu yang mengikuti ujian mengemudi demi mendapatkan surat izin mengemudinya merasa senang karena dia dan temannya dapat lulus dalam waktu yang bersamaan.

Kalimat data ini memiliki kesan maskulin dengan penggunaan kata “おれ (ore)” yang terkesan lebih mendekati danseigo. Penggunaan kata ini terkesan maskulin karena lebih sering digunakan oleh gender dengan sifat maskulin. Biasanya kaum pria menggunakan kata ini dalam penggunaan bahasa nonformal. Penggunaan kata maskulin lainnya untuk menggantikan orang pertama adalah “ぼく(boku)" yang menggunakan kanji “僕”、kata “わがはい (wagahai)” dengan kanji “吾輩”, “わし (washi)” dengan kanji “儂” sebagai danseigo yang sering digunakan dalam bahasa nonformal, dan”われ (ware)" dengan kanji “我” sebagai danseigo yang sering digunakan dalam bahasa formal. Dapat dipastikan bahwa penutur dialog tersebut merupakan orang dengan gender maskulin, yaitu Yuu. Hal ini sesuai dengan situasi yang digambarkan bahwa kalimat ini memang merupakan bagian dari monolog Yuu.

Penelitian Yuana (2018) juga menegaskan bahwa Ore adalah kata ganti orang pertama yang umumnya digunakan oleh pria usia remaja hingga orang tua terhadap teman sebaya, teman akrab, atau terhadap orang yang lebih rendah statusnya, 
serta memiliki kesan sangat akrab atau bahkan kasar.

\section{Kata Ganti Orang kedua (Nininshou Daimeishi)}

Penggunaan kata ganti orang kedua biasa digunakan untuk menunjuk lawan bicara yang menuturkan kalimat mereka. Penggunaan kata ganti ini merujuk kepada kata "kamu", "anda", "engkau" dan lain sebagainya untuk menunjukkan identitas subjek dari kalimat yang dituturkan.

Data 4.

マキエ、あなたもあの病院に勤めているなら噂く らい聞いたことあるでしょ?

Makie, anata mo ano byouin ni tsutomete iru nara uwasa kurai kiita koto aru desho?

(Kataoka, 2008, hal. 198)

マキエ/あなた/も/あの/病院/に/勤めている/な ら/噂/くらい/聞いた/こと/ある/でしょ

Makie/kamu/ par/ itu/ rumah sakit/ par/ bekerja/ kalau/ rumor/ Cuma/ dengar/ hal/ ada/ kan

'Makie, kalau kamu sudah lama bekerja di RS itu, kamu pasti sudah dengar gosipnya, kan?'

(Kataoka, 2015, hal. 196)

Data 4 merupakan dialog Yuka kepada Makie saat mereka sedang mengejar Yuu dan Setsumi sampai ke Shiga. Di perjalanan, Yuka menceritakan kisah pasien $L 7$ yang pernah kabur seperti Yuu dan Setsumi. Yuka membantu pelarian si pasien yang ternyata merupakan sahabatnya. Yuka menceritakan bahwa pada akhir hayatnya, sahabatnya memberikan mobil pelarian mereka kepadanya, dan mobil itu adalah mobil yang mereka tumpangi sekarang.

Kalimat data ini memiliki kesan feminim dengan penggunaan kata “あなた (anata)” yang terkesan lebih mendekati joseigo. Penggunaan kata ini terkesan feminim karena penggunaan kata ini lebih sering digunakan oleh gender dengan sifat feminim. Hermawan dan Rosliana (2013) mengatakan bahwa benar adanya jika penggunaan "anata" biasa digunakan oleh pria maupun wanita, namun kaum wanita lebih biasa menggunakan kata ini dalam bahasa formal. Bahkan kata ini dianggap lazim dan formal sebagai panggilan oleh kaum wanita kepada suaminya. Hermawan dan Rosliana (2013) juga menegaskan bahwa pronomina anata hanya dapat dipakai saat pertama kali bertemu dengan lawan bicara dalam situasi formal. Berdasarkan paparan tersebut, maka dapat dipastikan bahwa penutur dialog tersebut merupakan orang dengan gender feminim, yaitu Yuka atau Makie. Hal ini sesuai dengan referensi yang telah disampaikan setelah membaca kalimat di atas bahwa penutur merupakan lawan bicara dari Makie, yaitu Yuka.

Pada contoh selanjutnya kita juga akan melihat bagaimana penggunaan pronomina persona kedua digunakan oleh pria.

Data 5.

なあ、お前.......そのテレビ面白いか?

Naa, omae... sono terebi omoshiroi ka?

(Kataoka, 2008, hal. 30)

なあ/お前/その/テレビ/面白い/か

Nah/ kamu/ itu/televisi/ menarik/ par

'Hei, kau... Memangnya acara di TV itu menarik?'

(Kataoka, 2015, hal. 27)

Data 5 di atas merupakan dialog Yuu pada saat dia bertemu dengan Setsumi untuk pertama kalinya. Yuu yang baru saja mendapat kabar bahwa dia harus memasuki RS khusus penyakit kronis, merasa hidupnya telah hancur. Di sana, ia melihat seorang anak kecil terduduk memandangi televisi dengan tatapan kosong. Dia yang merasa harus menegur si gadis akhirnya melontarkan pertanyaan tersebut.

Kalimat data ini memiliki kesan maskulin dengan penggunaan kata “おまえ (omae)” yang terkesan lebih mendekati danseigo. Penggunaan kata ini terkesan maskulin karena penggunaan kata ini lebih sering digunakan oleh gender dengan sifat maskulin, karena biasanya kaum lelaki menggunakan kata ini dalam penggunaan bahasa nonformal. Penggunaan kata maskulin lainnya untuk menggantikan orang pertama adalah “てめ え (temee)” yang menggunakan kanji “手前”、kata “きさま (kisama)” dengan kanji “貴様” yang sering digunakan dalam bahasa nonformal, dan " なんじ (nanji)” dengan kanji “汝” sebagai danseigo yang sering digunakan dalam bahasa formal. Dapat dipastikan bahwa penutur dialog tersebut merupakan orang dengan gender maskulin, yaitu Yuu. Setelah melihat kalimat sebelumnya, “... Kanojo mo onaji tachiba dearu to iu [genjitsu] ga, me no mae ni tatakitsukerareta tame kamoshirenai", kalimat ini merupakan bagian dari monolog Yuu. Maka memang benar bahwa penutur merupakan Yuu yang mulai mengajak bicara gadis yang dimaksud. 


\section{Kata Ganti Orang Ketiga (Sanninshou Daimeishi)}

Penggunaan kata ganti orang ketiga biasa digunakan untuk menunjuk orang lain selain lawan bicara maupun pembicara yang menuturkan kalimat pada dialog mereka. Penggunaan kata ganti ini tidak harus merujuk kepada orang yang tampak oleh penutur maupun lawan bicaranya, melainkan merujuk kepada seseorang yang penutur maupun lawan bicara ketahui tanpa adanya makna abstrak. Penggunaan kata ganti ini merujuk kepada kata "dia", "beliau", penggunaan kata tunjuk terhadap kata benda dengan kata "itu" maupun "ini", dan lain sebagainya untuk menunjukkan identitas subjek dari kalimat yang dituturkan

Data 6.

佐倉さん......あなたはご自分のお娘さんが心配で はないのですか?

Sakura san... anata wa gojibun no omusume san ga shinpai dewa nai no desu ka?

(Kataoka, 2008, hal. 95)

佐倉さん/あなた/は/ご自分/の/お娘さん/が/心 配/ではない/の/です/か

Ibu Sakura/ kamu/ par/ diri sendiri/ par/ anak perempuan/ par/ khawatir/ tidak/ par/ apakah 'Ibu Sakura... Anda nggak mengkhawatirkan putri anda, ya?'

(Kataoka, 2015, hal. 92)

Data 6 di atas merupakan dialog antara Makie dan ibu Setsumi. Makie merasa ibu Setsumi kelihatan tak acuh terhadap anaknya yang hilang bersama dengan Yuu. Makie merasa ibu Setsumi sama dengan ayahnya Yuu yang hanya memikirkan dirinya sendiri, tanpa peduli apa yang terjadi kepada anaknya. Karenanya Makie memberanikan diri untuk melontarkan pertanyaan tersebut.

Kalimat data ini memiliki kesan feminim dengan penggunaan kata “お娘さん (omusumesan)" yang terkesan lebih mendekati joseigo. Penggunaan kata ini terkesan feminim karena lebih sering digunakan oleh Gender dengan sifat feminim. Biasanya kaum wanita menggunakan kata ini dalam penggunaan bahasa formal. Penggunaan kata feminim lainnya juga terlihat pada kata “ご自分 (gojibun)” dan “のです か (no desu ka)" yang sering digunakan dalam joseigo pada bahasa formal. Maka dapat dipastikan bahwa penutur dialog tersebut merupakan orang dengan gender feminim, yaitu Makie dan ibu Setsumi. Hal ini sesuai situasi yang digambarkan di mana kalimat ini memang merupakan bagian dari dialog yang dilontarkan kepada ibu Setsumi oleh Makie. Hal ini diperkuat oleh data penelitian oleh Yuana (2018), bahwa penggunaan prefiks " $O$ " dan "Go" biasa digunakan oleh kaum wanita, memiliki keformalitasan dan tidak terlepas dari sufiks -san yang terkesan formal pula.

Pada contoh 7 kita juga akan melihat bagaimana penggunaan pronomina persona ketiga digunakan oleh pria.

Data 7

ならば頃合いまでどこかで時間を潰している可能 性が高い。

Naraba koroai made dokoka de jikan wo tsubushiteiru kanousei ga takai.

(Kataoka, 2008, hal. 76)

ならば/頃合い/まで/どこか/で/時間/を/潰 している/可能性/が/高い

Maka/ jam pas/ par/ di mana/ par/ di jam/ par/ sedang menghabiskan/ kemugkinannya/ par/ besar 'Kalau begitu, kemungkinan besar pengguna mesin cuci ini pergi ke suatu tempat untuk menghabiskan waktu sampai waktu pengeringan selesai.'

(Kataoka, 2015, hal. 71)

Data 7 merupakan monolog Yuu saat mendatangi area laundry yang dia temukan di pinggir jalan. Yuu sedang melihat keadaan sekitar dan juga bagian dalam toko untuk mengetahui apakah ada orang atau tidak. Dia ingin mengetahui hal ini agar bisa mengetahui apakah rencananya untuk mencuri beberapa pakaian untuk dia dan Setsumi pakai akan berhasil atau sebaliknya. Setelah mengecek semuanya, dia berpendapat bahwa pemilik baju yang ada di dalam mesin cuci sedang tidak ada di tempat.

Kalimat data ini memiliki kesan maskulin dengan penggunaan kata “ならば (naraba)” yang terkesan danseigo. Penggunaan kata ini terkesan maskulin karena penggunaan kata ini bersifat nonformal. Bentuk formal atau yang lebih feminim dari kata tersebut bisa digantikan dengan kata “ですから (desukara)". Dapat dipastikan bahwa yang menuturkan monolog ini adalah orang dengan Gender maskulin, yaitu Yuu.

Dengan Yuu sebagai penutur, penggunaan kata “pengguna mesin cuci" dapat diganti dengan “彼 (kare)”. Penggunaan “彼 (kare)” dianggap lebih tepat karena berdasarkan referensi yang ada, si penutur terbiasa mengunakan kata yang langsung 
menunjuk kepada orang yang dimaksud. Dibandingkan dengan menggunakan bahasa yang berbelit-belit seperti kata “これを使う人 (korewo tsukau hito)" atau “この洗濯機を使う人 (kono sentakuki wo tsukau hito)", Yuu lebih sering terlihat menggunakan kata langsung yang lebih menujukan kepada lawan bicara. Sebagai contoh, "naa, omae... sono terebi omoshiroika?". Dengan referensi tersebut, dapat dikonfirmasikan bahwa kata ganti orang pertama yang akan dituturkan oleh Yuu untuk pengganti kata "pengguna mesin cuci" adalah kare(彼).

Hal ini juga diperkuat dengan penelitian Hermawan dan Rosliana (2018) yang mengatakan bahwa pronomina kare mengacu orang lain yang dibicarakan yaitu pria. Selain itu bisa juga digunakan untuk menyebut kekasih (pria), meskipun bentuk yang lebih lazim digunakan adalah kareshi.

\section{SIMPULAN}

Dengan adanya perbedaan bahasa laki-laki dan perempuan pada contoh kalimat yang telah ditunjukkan, kita dapat menyimpulkan bahwa dalam penggunaan kata ganti orang pertama, kedua, dan ketiga, kata yang digunakan berbeda sesuai gender sang penutur. Kaum wanita terlihat lebih menggunakan kosakata yang lebih halus dibanding kaum pria pada umumnya. Pada pronomina persona pertama dan kedua kaum pria cenderung memilih dan menggunakan kosakata yang terkesan lebih kasar, sedangkan kaum wanita cenderung memilih dan menggunakan kosakata yang terkesan lebih halus. Pada pronomina persona ketiga, kaum wanita lebih cenderung menambahkan awalan " $O$ " atau "Go" di depan meishi yang dimaksudkan untuk menghormati lawan bicara, sedangkan kaum pria cenderung mengabaikan formalitas. Walaupun memiliki perbedaan, tiap-tiap penutur dapat saling memahami satu sama lain. Hal ini terjadi karena tiap gender dapat memahami siapa lawan bicara mereka, dan apa yang harus mereka ucapkan berdasarkan sisi referensi dan juga situasi sehingga mengetahui kata yang tepat untuk dituturkan terhadap lawan bicara dengan perspektif masingmasing. Penelitian ini diharapkan dapat membantu para penutur bahasa asing agar lebih memahami perubahan-perubahan yang terjadi pada pronomina persona pada bahasa Jepang, terutama dalam bahasa percakapan.

\section{REFERENSI}

Alwi, H., Soenjono, D., Lapoliwa, H., \& Moeliono, A. M. (2010). Tata Bahasa Baku Bahasa Indonesia. Jakarta: Balai Pustaka.

Artika, I. W. (2015). Teori dalam Pengajaran Sastra. Prasi: Jurnal Bahasa, Seni dan Pengajarannya, 10(19), 18-27. hhttp://dx.doi.org/10.23887/prasi.v10i19.8850

Hermawan, N., \& Rosliana, L. (2013). Pronomina Persona dalam Novel Naifu dan Terjemahannya dalam Bahasa Indonesia. Japanese Literature, 2(3), 111. Retrieved from eJournal Undip.

Kataoka, T. (2008). Narcissu. Tokyo: Kadokawa Corporation.

Kataoka, T. (2015). Narcissu. (D. Agung, Trans.). Jakarta: PT Eaststar Adhi Citra.

Kridalaksana, H. (1992). Pembentukan Kata dalam Bahasa Indonesia. Jakarta: PT Gramedia Pustaka Utama.

Rini, E. I. H. A. N. (2018). Konjungsi Baai dalam Kalimat Bahasa Jepang. Kiryoku: Jurnal Studi Kejepangan, 2(1), 33-40. https://doi.org/10.14710/kiryoku.v2i1.33-40

Sudjianto, S., \& Dahidi, A. (2012). Pengantar Linguistik Bahasa Jepang. Jakarta: Kesaint Blanc Publishing.

Tanaka, H. (1982). Gengogaku Enshuu. Tokyo: Taishukan Shoten.

Yuana, C. (2018). Perbedaan Ichininsho Daimeishi menurut Gender. Parafrase: Jurnal Kajian Kebahasaan \& Kesastraan, 18(2), 7-18. https://doi.org/10.30996/parafrase.v18i2.1717 